\title{
CONCEPTOS RELIGIOSOS Y VIDA RELIGIOSA
}

ALEJANDRO TOMASINI BASSOLS

INSTITUTO DE INVESTIGACIONES FILOSÓfICAS

Universidad Nacional Autónoma de México

Spinoza hace en la Ética una afirmación que, en caso de ser verdadera, tendría repercusiones de magnitudes dificiles de evaluar y, desde luego, imposibles de minimizar. Él sostiene que "Una afección que es una pasión deja de ser una pasión tan pronto como nos formamos de ella una idea clara y distinta."l No es mi objetivo en este ensayo discutir lo que Spinoza dice, examinar su "prueba", etc. sino, más bien, asumir la idea, tomarla como punto de partida y aplicarla en el terreno de la religión o de lo que, empleando su terminología, podríamos llamar 'pasiones religiosas'. ¿Podría acaso ser cierto que, una vez comprendidas las fuentes de las creencias religiosas, una vez comprendida la "lógica" del discurso religioso, la religión se desvanece? La tesis por la que abogaré en este ensayo no es tan fuerte, aunque debo decir que sí pienso que ciertas formas de religión quedarían excluídas para quien efectuara con éxito una investigación gramatical de los conceptos religiosos clave. Lo que se perdería, empero, sería tan sólo el aspecto o carácter irracional de la religión (de cuya existencia ni el teísta más fanático podría dudar), pero se reforzaría, en cambio, el ético y el personal. Espero mostrar que éste es, en efecto, un resultado al que lleva el análisis de tres conceptos religiosos de los que me ocuparé aquí, a saber, los conceptos de fe, Dios y rezo. Antes de dar comienzo al examen, no obstante, creo que será conveniente declarar que pienso hacer uso del instrumental conceptual de Wittgenstein, tanto del primero como del segundo, entre otras razones porque pienso que Wittgenstein no modificó sustancialmente sus puntos de vista en relación con estos temas. Asimismo, es mi objetivo presentar aspectos de su pensamiento no siempre fáciles de discernir y comprender, pero debo decir desde ahora que enuncio también puntos de vista que no estoy seguro de que podríamos con certeza hacer pasar por suyos. Espero que la redacción logre evitar estas confusiones posibles. Lo que, independientemente de ello, sí mantengo es que la posición alcanzada, correcta o no, es algo que sólo el aparato conceptual wittgensteiniano

1 B. Spinoza, Etica demostrada según el Modo Geomterico., Prop. III, Libro V, GarnierFlammarion, París, 1965, p. 307. 
permite construir. Iniciemos, pues, nuestro trabajo de aclaración conceptual examinando la noción de fe.

Parece evidente que una pregunta, la única tal vez, que no tendría mayor objeto plantear, por lo menos al inicio de la investigación, es la pregunta '¿qué es la fe?', puesto que dicha interrogante no nos orienta en lo más mínimo en cuanto a lo que sería una posible respuesta (defecto o debilidad típica de las preguntas de tipo ‘¿Qué es $X$ ?’). La respuesta a la pregunta acerca de qué sea la fe se obtiene más bien esclareciendo el concepto de fe (lo cual requiere, entre otras cosas, que se especifiquen sus condiciones de aplicación) y esto es precisamente lo que por lo menos, en principio, se logra en la investigación gramatical. Nuestro punto de partida debe, pues, ser otro. ¿Cuál podrá ser dicho punto?

Desde la perspectiva wittgensteiniana, esto es, cuando lo que se desea es recurrir a la metodología wittgensteiniana, la reflexión no puede más que iniciarse con la consideración minuciosa, lo más detallada y exacta posible, de las expresiones usuales en las que la "palabra-concepto" aparece (en este caso, 'fe'). Es claro, por otra parte, que no es la mera palabra, esto es, el signo, lo que está en juego, sino más bien el signo aplicado, es decir, las expresiones usadas en las que él es un componente. Propongo por consiguiente examinar la noción de fe en conexión:

1) con alguien, $y$

2) con algo

Independientamente de si el uso religioso de "fe" es de hecho el uso original o no, lo cierto es que empleamos la palabra en conexión con personas y en una multitud de situaciones diferentes. Muy a menudo, por ejemplo, se usa la expresión para hablar de un líder político. Por ejemplo, habría sido perfectamente legítimo para los bolcheviques de la vieja guardia decir que "tenían fe" en Lenin; o si se prefiere, sería perfectamente legítimo para nosotros describir su conducta hacia él como una conducta de fe. Ahora bien, esto habría podido significar diversas cosas, como por ejemplo:

a) que estaban firmemente convencidos de que bajo su dirección su programa tendría éxito

b) que consideraban que de todas las propuestas que se óan las de Lenin les resultaban sistemáticamente más convincentes y sensatas

c) que siempre que era necesario articular una explicación recurriendo a una teoría (grosso modo, el marxismo) la de Lenin resultaba ser la más lograda

d) que cuando había que subir a la tribuna el mejor orador cra Lenin

e) que el líder carismático era Lenin, etc. 
Ahora bien, no creo que pueda cuestionarse que si alguien tuvo fe en Lenin (o en cualquier otro líder) ello se debió, entre otras razones, a que era un hombre inteligente, perspicaz, experimentado, valiente, etc. En otras palabras, para que la gente hubiera podido tener fe en él, Lenin tuvo que pasar los "tests" relevantes y fue porque pasó las pruebas que la vida le impuso que la gente sentía que podía "tener fe" en él. Lo mismo acontece, mutatis mutantis, en otros casos, como cuando se dice que se tiene fe en un hijo o en un joven artista o intelectual o deportista, etc. Claro que la fuerza o, incluso, la relevancia de la expresión 'tengo fe en él' depende un poco del contexto: la noción de fe es demasiado "seria", alude a un compromiso demasiado grande para aplicarla a personajes o contextos o situaciones, en un sentido terrenal, intrascendentes.

Lo que estas consideraciones permiten inferir son, por lo pronto, dos cosas:

1) Cuando se tiene fe en alguien concreto es porque se tienen razones para tener fe. La fe secular, y esto es analíticamente verdadero (o, si se prefiere, es una verdad gramatical), es a posteriori. No se tiene fe en alguien porque se quiere. La fe secular es, en cierto sentido o hasta cierto grado, justificable. Puede incluso perderse la fe en alguien en quien se la tenía. No es un sinsentido decir de alguien que, por razones que podrían enunciarse, se dejó de tener fe en él (o en ella).

2) La fe que se puede tener en alguien cubre un sector o un ámbito de vida, por amplio que éste sea. Eventualmente, si la persona en quien se tiene fe es particularmente dotada, nuestra fe en ella puede cubrir diversos campos, pero es muy poco plausible que se esté justificado en tener fe en una persona en todos los contextos. Por ejemplo, es claro que podemos tener fe en Lenin en cuanto a política atañe, pero esto no nos compromete con él en el terreno, e.g., del deporte. Puede ser que su "ojo" para juzgar cuadros fuera excelente, que fuera un gran crítico de pintura o incluso un creador él mismo y podríamos aceptar sus juicios en forma incondicionada respecto a la pintura, pero no está implicado que e.g., su "oído" fuera de la misma calidad y sería posible que sus gustos musicales fueran simples o toscos. Luego la fe secular es parcial o limitada o restringida, por intensa que sea.

Resumiendo: dos rasgos centrales de la "fe laica", que el escrutinio del lenguaje nos permite detectar, son su carácter a posteriori y su carácter restringido o parcial.

Frente a este uso laico de "fe", tenemos el uso religioso. Una diferencia notable es que en el primer caso la noción se aplica a una persona, en tanto que en el segundo se aplica, fundamental si no es que exclusivamente, a Dios. Nuestra pregunta es, por lo tanto, ‘¿Qué es tener fe en Dios?’. Y, una vez más, la respuesta no puede proceder más que del examen del lenguaje fideísta, aplicado sensatamente en situaciones concretas.

Deseo sostener, en primer lugar, que es contradictorio creer en Dios y no tener fe en Él. Esto no me compromete con la creencia en Dios: mi afir- 
mación pretende ser una observación gramatical. Estoy tan sólo afirmando que una determinada conjunción de aseveraciones es ininteligible. No es que sea lógicamente absurda, pero sí conceptualmente absurda. Permitiéndome por el momento usar un lenguaje que más abajo critico y rechazo, pienso que puede afirmarse que Dios es, justamente, aquel "ser" en quien podemos tener una confianza total ("tener fe" implica "tener confianza", si bien la inversa no vale), el "ser" en quien puede uno entregarse pase lo que pase. Esto quiere decir que la fe en Dios es a priori y lo es en el siguiente sentido: la fe del creyente genuino es independientemente de la experiencia. Los eventos del mundo no pueden ni engendrarla ni destruirla. Es por eso que no se puede dotar de sentido a la expresión 'perder la fe en Dios'. La fe religiosa no resulta de un cálculo, de una inferencia, etc. Dios no es puesto a prueba. Es más bien a la inversa: Él pone a prueba al creyente y mide su fe. Nosotros cuantificamos la fe de un hombre en función de qué tan incólume se mantenga ésta frente a las desgracias que lo acosen. Es por esto que Wittgenstein afirma que "La fe religiosa y la superstición son completamente diferentes. Una de ellas resulta del miedo y es una especie de ciencia falsa. La otra es un confiar". ${ }^{2}$ Esto nos lleva a un segundo punto.

En contraposición con la fe que se puede tener en alguna persona en particular, la fe en Dios cubre, por así decirlo, el todo de nuestra experiencia, el todo de nuestra vida. Es el resultado de una mala interpretación pensar que con Dios se puede negociar y que podemos tener fe en Él para asuntos concretos. Se aplica con propiedad la expresión, e.g., 'Tengo fe en Dios', cuando lo que queremos expresar es un sentimiento de estar protegidos o cuidados a pesar de las vicisinudes de nuestra existencia, es decir, cuando estamos reconciliados con nuestra vida o la "aceptamos" tal cual es o fue. Sobre esto regresaré más adelante. Por el momento, percatémonos de que el problema es que este modo de hablar (es decir, estar protegido, sentirse cuidado, etc.) no permite expresar lo que realmente queremos decir. Es por eso que todo lo que se intenta expresar acerca de la totalidad de nuestras experiencias, del mundo como un todo, etc., en el lenguaje laico o científico (esto es, en un lenguaje no religioso), tendrá como resultado un sinsentido. Wittgenstein explica esto en su Conferencia sobre la Ética. Una de las experiencias religiosas de las que él habla es la experiencia de "sentirse absolutamente a salvo. Quiero decir el estado anímico en el que uno se inclina a decir 'Estoy a salvo, absolutamente nada de lo que suceda puede lastimarme'". ${ }^{3}$ (Esto es, probablemente, otro modo de decir que se "tiene fe".) La primera reacción es protestar y decir que no sólo no es inexpresable dicha experiencia o dicho estado, sino que Witte-

2 L. Wittgenstein, Culture and Value, Basil Balckwell, Oxford (1979), p. 72.

3 L. Wittgenstein, A Lecture on Ethics, editada en el texto de The Open University: Thought and Reality Central Themes in Wittgenstein's Philosophy, Unidades 27-28, The Open Unversity Press, Manchester (1976), p. 65. 
genstein la ha hecho comprensible, la ha expresado. Pero esto es una ilusión, como todas las de la filosofía, fundada en una incomprensión de la lógica de nuestro lenguaje. "Todos sabemos lo que en la vida cotidiana significa estar a salvo. Estoy a salvo en mi cuarto, cuando no puede atropellarme un autobús. Estoy a salvo si tenía tos ferina y ya no puedo, por lo tanto, volverla a tener. Estar a salvo significa esencialmente que es físicamente imposible que ciertas cosas me sucedan y, por lo tanto, es un sinsentido decir que estoy a salvo suceda lo que suceda. ${ }^{34} \mathrm{El}$ juego de lenguaje de la fe religiosa, podemos colegir, es lógicamente distinto del de la descripción del mundo o del de la expresión de sensaciones. Sobre esto regresaré más abajo, cuando intentemos dilucidar la función del lenguaje religioso. Baste por ahora anotar, sencillamente, que en contraposición con la fe laica, la fe religiosa es a priori y "total".

Pasemos ahora a considerar rápidamente los casos en lo que el lenguaje de la fe recae no ya sobre alguien, sino sobre algo. Esto es lo que sucede cuando afirmamos, en el lenguaje natural, cosas como 'tengo fe en que no estallará la tercera guerra mundial', 'tiene fe en que ganará en la lotería', 'tenemos fe en que acabaremos con la tuberculosis', etc. Salta a la vista que el uso de 'fe' en su aplicación a situaciones mundanas implica que quien tiene fe no sabe, no está seguro de aquello en lo que cree: puede tener razones, encontrarse en el estado mental que llamamos 'de confianza', etc., pero nada garantiza que su pensamiento sea verdadero. Este uso de 'fe' es eliminable o, por lo menos, reemplazable por los de otras nociones. Es notable el contraste en este punto con la fe religiosa "situacional". Es claro que al jugar el juego del lenguaje religioso uno puede hablar de fe en conexión con "situaciones" especiales. Por ejemplo, puede decirse que se tiene fe en la resurreción de la carne, en la bondad divina, en la superioridad de Dios frente a Satanás, en la efectividad de las plegarias, etc. La fe en estos casos tiene tres características definitorias:

1) quien tiene fe se siente seguro. No duda,

2) quien tiene fe actúa de cierto modo (i.e, en concordancia con ella),

3) quien tiene fe es un usuario normal del lenguaje religioso institucionalizado (puesto que es en este lenguaje que se formulan las "situaciones" en las que "se cree"). Esta clase de fe, por lo tanto, está lógicamente ligada al dogma.

Pienso que la fe religiosa en algo está subordinada a la fe religiosa en alguien (i. e, en Dios) y deseo sostener que esta última no tiene por qué recibir una interpretación teísta convencional. $\mathrm{Si}$ esto fuera como sugiero, se nos abrirían las puertas para la legitimización de una "religión" no-teísta. Tendré más que decir sobre esto, pero ahora quisiera considerar el caso de "Dios", su aplicación y su utilidad. 
Empecemos nuestra disquisición con la construcción de un caso. Imaginemos que dos personas, $A$ y $B$, son íntimos amigos. Han crecido juntos, han trabajado juntos, han viajado juntos, etc., de tal modo que los une un fuerte vínculo sentimental de amistad fundada en acciones y hechos. Ellos se han ayudado mutuamente. Sus familias también son amigas entre sí. Supongamos ahora que $A$ tiene en perspectiva negocios productivos y un matrimonio prometedor. De todo ello, evidentemente, está al tanto su confidente y amigo $B$. No obstante, ignorado por todos, una envidia profunda corroe a $B$, a quien inesperadamente se le presenta la posibilidad de reemplazar a $A$, tanto en el mundo de los negocios como en el de la vida afectiva conyugal. $B$ de pronto se da cuenta de que tiene la oportunidad de ocupar el lugar de $A$ y de obtener todo lo que la vida le ofrece a este último. Para ello, sin embargo, tiene que traicionar a su amigo. Imaginemos que es más fuerte la ambición que cualquier otra "pasión" y que $B$ arruina a su amigo y desposa a su prometida. $A$ es encarcelado y en el calabozo, desesperado y sin ya intentar comprender, se suicida. Desde un punto de vista legal, $B$, que está al tanto de todo lo padecido por $A$, está a salvo: nadie sabe que es él el culpable de la desventura de su amigo y -para realzar el carácter del caso- supongamos que nadie puede saberlo. Para colmo de ironías, es él quien recibe las condolencias más sinceras por parte de todos quienes los conocieron. A partir de ese momento, $B$ lleva una vida "feliz"; tiene todo lo que siempre anheló: una esposa que lo quiere y respeta, una situación social y pecuniaria excelente, etc. $B$ vive de este modo hasta que, al vislumbrarse ya el horizonte que marca el fin de su existencia, de pronto, se "inquieta". Aunque no hay nadie que le reproche nada, $B$ siente que, de uno u otro modo, tarde o temprano, habrá que "rendir cuentas". Supongamos ahora que ese hombre, o sea $B$, decide que no puede proseguir, porque está genuina, verdaderamente arrepentido. El sabe que nadie puede hacerle nada y, sin embargo, quiere, necesita pedir perdon. ¿A quien le va a pedir perdón? ¿A su amigo? Demasiado tarde: descansa en una lúgubre y perdida tumba. ¿Cómo hace ese hombre para expiar su culpa, para redimirse? ¿Qué puede hacer para acallar la voz de la conciencia o, por qué no decirlo, la voz de Dios? ("Ciertamente es correcto decir: la conciencia es la voz de Dios". $)^{5}$ Supongamos que $B$, auténticamente arrepentido, abandona su familia, sus amigos, cambia su mundo (en otras palabras, supongamos que el arrepentimiento es real, es decir, toma forma en acciones, en decisiones concretas). ¿Cómo podría un hombre así, un hombre desesperado, expresar su sentimiento? ¿Cómo podría un hombre, a salvo de la justicia humana pero que se autorepudia, poner en palabras la nueva perspectiva, la nueva actitud, el nuevo estado anímico, la nueva línea de conducta, cuando sabe que, para ciertos efectos, ya no hay nada que hacer? ¿No es acaso el lenguaje religioso 
el único posible, el lenguaje ad hoc, para ello? ¿No serían expresiones como 'Dios mío, iperdóname!', 'Dios mío, ihaz de mí lo que quieras!', 'Dios mío, te entrego mi alma', No me condenes, no me entregues a las llamas', etc. las únicas formas de expresión a las que podría recurrir, las únicas que tendrían sentido? ¿No es justamente esa la función del lenguaje religioso y no quedó formado el concepto religioso supremo, i. e, "Dios", para poder hablar sensatamente en situaciones como la descrita? Fijémonos en lo que dice Wittgenstein, hablando del caso particular de la religión que permea nuestra cultura: "La religión cristiana es sólo para el hombre que necesita ayuda infinita, es decir, únicamente para el hombre que padece un tormento infinito". ${ }^{6} \mathrm{Y}$ prosigue: "La fe cristiana -como yo la veo- es el refugio del hombre para este tormento último". P Pienso que Wittgenstein tiene razón y también que esto no lo obliga a sostener ni que ésta sea la única función de la religión ni que la salvación de la que él habla sea una prerrogativa de la religión cristiana. En este punto, pienso que habría que reconocer que las religiones son como las plantas: no todas pueden florecer en los mismos climas, pero siempre hay reemplazantes. No hay duda, sin embargo, de que de uno u de otro modo es una de las funciones de la religión la de "salvar el alma" del individuo, sea lo que sea lo que esto signifique.

La utilidad de un concepto se manifiesta a través de sus aplicaciones y la descripción de situaciones en las que el concepto en cuestión es empleado nos da la clave para su comprensión. Lo que podríamos llamar la metodología de Wittgenstein comporta, precisamente, la estrategia consistente en describir situaciones, tanto reales como imaginarias, tanto normales como inusuales, a fin de poner de relieve una u otra de las notas componentes de un concepto dado. Esto es precisamente lo que hemos tratado de hacer para ilustrar la utilidad del concepto de Dios. Otra de las opciones metodológicas wittgensteinianas consiste en describir el modo como una palabra es usada y, en particular, el modo como es introducida en el lenguaje, su juego de lenguaje original. En relación con 'Dios', creo que el relato de una situación real de la vida de Wittgenstein nos da la clave para entrever la significación de la palabra e iniciar el proceso de comprensión. Como se sabe, en los años 20 Wittgenstein fue durante más o menos 6 años maestro rural en una escuela primaria, en Austria. Su trayectoria como maestro ha sido paulatinamente reconstruida, de modo tal que estamos al tanto ahora de sus magnitudes como educador. Empero, lo que para nuestros propósitos es relevante, es una ocasión en la que, de regreso de Viena con sus niños, atravesando a pie un bosque a media-

6 L. Wittgenstein, Culture and Value, p. 46.

7 Ibid. p. 46. 
noche, Wittgenstein dialoga con sus alumnos del siguiente modo: “iTienes miedo? Bueno, entonces tienes que pensar únicamente en Dios". ${ }^{8}$

Esta "anécdota", contada por uno de sus ex-alumnos, revela no sólo muchas cosas de la personalidad de Wittgenstein, sino también de su concepción del lenguaje, en particular de su concepto de Dios y, por ende, de la divinidad misma. Una de las funciones del concepto de Dios es la de hacernos sentir a salvo en situaciones de temores "naturales" no especificados. Para que este concepto sea así aplicable es menester que algunos por lo menos de los rasgos fundamentales de Dios sean que:

a) Dios está en todas partes.

b) Dios todo lo sabe.

c) Dios es esencialmente protector.

d) Dios no es un ser de experiencia (no se le ve, no se le toca etc.).

Esto nos fuerza a concluir que la "lógica" de 'Dios' es distinta de la de 'mesa', 'perro', 'libro', 'Pedro', 'átomo', etc., es decir, es absurdo predicar de Dios cualquier cosa que se predique de los objetos genuinos: relaciones espaciotemporales (acordémonos de Yuri Gagarin: fui al cielo y no vi a Dios), relaciones causales y demás. El discurso acerca de la divinidad y sus derivados, i. e., el juego de lenguaje religioso en general, cumple, pues, otra función que la del juego de lenguaje científico y descriptivo. La religión no es ni protociencia ni super-ciencia. Otra, manera de presentar la idea es decir que Dios no es un objeto ni un "ser". El lenguaje religioso es comprensible sólo a través del examen de las prácticas con las que está asociado y éstas no nos ponen en conexión con un ser. La fe religiosa, el discurso sobre Dios, las plegarias, etc. no tienen, por lo tanto, nada que ver con la explicación del mundo, sino más bien con su "contemplación" y "adoración".

Los conceptos religiosos forman un sistema, de tal modo que el examen de unos lleva en forma natural a otros. Es normal hablar de fe en conexión con Dios, por ejemplo. Pienso incluso que podemos hacer una afirmación más fuerte y sostener que la comprensión de unas de las nociones religiosas requiere la comprensión de otras. En particular, pienso que sólo si se comprende la gramática de expresiones como 'Dios existe', 'Creo en Dios', etc. se puede tener una idea adecuada de los que es rezar u orar. Puede decirse, en una primera caracterización, que rezar es hablar con Dios o, mejor dicho, hablarle a Dios (para confesarse, para suplicar, etc.). Ahora bien, dado que, como he argumentado, el juego de lenguaje religioso no es asimilable ni al ordinario ni al científico, se sigue que el uso de 'hablarle a Dios' no es equiparable al uso de

8 W. D. Hudson, Wittgenstcin and Religious Belief, The Macmillan Press Ltd., Londres (1975), p. 103. 
'hablar', cuando lo que una persona hace es dirigirse a otra o a un animal o incluso a una cosa. Una vez más, "hablarle a Dios" es un simil, una imagen. ${ }^{9}$ Por otra parte, un rezo, en el sentido usual de la palabra, es un rito y, por lo tanto, es un modo institucionalizado de "hablarle a Dios". Es una práctica social en la que cada individuo se ejercita por sí solo, en forma individual. Es, por lo tanto, una práctica a la que tiene acceso sólo quien está inmerso en alguna forma de vida religiosa institucionalizada. Ahora bien, ¿Cómo aclararnos a nosotros mismos el significado del rezo o plegaria u oración? Lo primero por observar es, quizá, que la palabra 'rezar' sirve para englobar toda una variedad de discursos dirigidos a Dios. Al rezar, un hombre puede confesarse, pedir perdón, dar gracias, etc. En algunas ocasiones un hombre necesita "purificar su corazón"; en otras lo que desea es calmar su ansiedad o su aprensión; en otras más, manifestar su aceptación de lo que sucede, y así sucesivamente. En esas ocasiones, el rezo tiene sentido. El rezo es el inductor religioso de las emociones religiosas (arrepentimiento, purificación, resignación, etc.). Pero ¿es el rezo indispensable a toda vida religiosa?

En los Notebooks, Wittgenstein hace una declaración sosprendente: "Rezar", nos dice, "es pensar acerca del sentido de la vida". ${ }^{10}$ Esta afirmación choca con la concepción usual de lo que es rezar, esto es, la que dimos anteriormente, viz., hablarle a Dios. La diferencia se origina en el hecho de que en la concepción usual 'Dios' es usado como el nombre propio de un ser especial y 'hablar' es empleado básicamente en el mismo sentido que en la vida cotidiana. Rezar es entonces dirigirse al ser supremo, lo más a menudo para solicitar de Él que intervenga y altere el decurso de la naturaleza. Esto, habrá que reconocerlo, es superstición, fundada en una incomprensión lógica, y es obvio que no puede ser ésta la concepción de alguien no supersticioso pero que, por otra parte, requiere del lenguaje religioso. "Dios", se nos dice en el Tractatus, "no se revela en el mundo" 11 y es claro que fuera del mundo no hay nada. El esclarecimiento del concepto de Dios no corresponde, por lo tanto, a la interpretación convencional. Ya hemos dicho algunas cosas acerca de Él pero, para completar nuestro examen, regresemos a los Notebooks, porque allí Wittgenstein da indicaciones precisas acerca de lo que entiende por 'creer en Dios' y ellas serán lo que permitirá que se nos aclare su concepción del rezo.

Nuestro pensamiento no es sino una figura lógica de los hechos y, en realidad, no puede manifestarse más que a través de las proposiciones. Pero ¿qué es una proposición? La respuesta de Wittgenstein es que "una proposición es un signo proposicional en su relación proyectiva con el mundo". 12 O sea, una vez

9 Cfr. Lecture on Ethics, p. 65.

10 Notebooks, p. 73. 6.432 .

11 L. Wittgenstein, Tractatus Logico-Philosophicus, Routledge \& Kegan Paul, Londres (1978),

12 Ibid, 3.12 . 
que disponemos de signos, a los que adjudicamos en forma arbitraria significados, y una vez que hemos establecido las reglas de formación de expresiones complejas, es decir, la gramática del simbolismo, podemos establecer correlaciones de tal modo que un hecho del mundo (un signo) represente a otro, el hecho representado por el signo proposicional aplicado, i. e., pensado, ya que, como Wittgenstein dice, un pensamiento no es otra cosa que "un signo proposicional aplicado". ${ }^{13}$ En nuestros esfuerzos por describir el mundo a lo más que podemos aspirar es a tener una figura del mundo, es decir, a representárnoslo mediante la totalidad de pensamientos verdaderos ( $C$ fr. 3.01). Hasta allí llega el lenguaje, esto es, tocamos de este modo los límites de la significatividad. Lo importante, sin embargo, es que Wittgenstein insiste en que esto no es más que una cara de la moneda: al entender y ver que eso es todo lo que podemos decir, entendemos y vemos que hay algo que no podemos decir. Sabemos que el mundo es la totalidad de los hechos y que no podemos salirnos del mundo, es decir, del reino de la factualidad, pero no en otra cosa consiste justamente sentir que el mundo es un todo y si podemos sentir que el mundo es un todo es porque podemos sentir, más no decir, que hay algo más que ese todo. Ese algo más es su sentido. "Al significado de la vida, i. e., al significado del mundo, lo podemos llamar Dios". 14 Esto, obsérvese bien, no es una definición ni una estipulación: es una aclaración acerca de la lógica de la palabra 'Dios'. Por otra parte, también en los Notebooks afirma Wittgenstein, lo cual ya no nos resultará ininteligible, que "Creer en Dios significa ver que los hechos del mundo no son el fin del asunto". ${ }^{15}$ Recurriendo implícitamente a lo que sí es una mera cuestión de definición -el contacto con Dios es lo que se llama 'experiencia mística'- Wittgenstein nos dice ahora que "Sentir el mundo como un todo limitado - es eso lo que es místico". ${ }^{16}$ Se nos aclara entonces por qué rezar es efectivamente pensar en el sentido de la vida: rezar es pensar en Dios y Dios es el sentido del mundo, lo único que está más allá de la realidad y, por lo tanto, del lenguaje. No es, pues, mediante nuestro lenguaje que podríamos, por así decirlo, atraparlo. Dios no es descriptible o enunciable: Él sólo se muestra. Pienso, por consiguiente, que podemos ya articular una cierta respuesta a la pregunta formulada un poco más arriba acerca de la indispensabilidad del rezo. La respuesta que yo estoy en posición de proporcionar, empero, no puede, desafortunadamente, ser más que condicional, Si por 'rezo' se entiende un diálogo (cabría preguntar en qué idioma) o por lo menos una plegaria a un ser especial (un objeto para el cual, en principio, podríamos tener incluso criterios de identidad), entonces soy de la opinión de que el rezo no es indispensable a la vida religiosa. Creo, por el contrario,

\footnotetext{
13 Ibid., 3.5.

14 Notebooks, p. 73.

15 Ibid., p. 74.

16 Tractatus, 6.45 (b).
} 
que si el rezo es entendido como el esfuerzo lingüístico por expresar lo que un lenguaje descriptivo necesariamente deja escapar, i. e., el sentido del mundo, entonces el rezo es parte esencial de la vida religiosa. Pero, en ese caso, el rezo no tiene por qué revestir la forma de un texto que se repite una y otra vez. En la concepción que promuevo, los mejores intentos por rezar parecen ser los de gente como Walt Whitman, San Juan de la Cruz, Tolstoy, etc. El rezo es, desde esta perspectiva, personal y creador ("Ética y estética son lo mismo"). ${ }^{17}$

Aunque, como dije, pienso que los conceptos religiosos forman una red, es decir, se sostienen unos a otros (lo cual quiere decir que es absurdo o inútil buscar su "justificación" en conceptos de otras clases o intentar "reducirlos" a otros), es el suyo un uso que puede recibir diversas interpretaciones, por lo que tanto su empleo como las prácticas religiosas son fácilmente distorsionables. No es posible negar que, en general, el juego del lenguaje religioso es puesto en el mismo plano que, e.g., el de la física y que, por lo tanto, en general se hace de la religión mera superstición. Lo que por mi parte aquí deseo promover y defender es, en cambio, el punto de vista de que hay manera de salvarlo, erradicando de nuestra visión la interpretactión convencional. Para ello, es imprescindible extraer o detectar lo que sería la columna vertebral de la religión. Por razones esbozadas a lo largo del trabajo, niego que la trascendencia constituya el núcleo de la religión. Creo que son más bien ciertas emociones y experiencias las que están en su raíz. Esto, empero, requiere desarrollo y discusión.

En el Tractatus - y posteriormente con mucha más sofisticación en las Investigaciones Filosoficas y en Zettel-Wittgenstein rechaza el sujeto metafísico, el "yo", el ego o, en otras palabras, el alma humana. Son muchas las líneas de pensamiento que conducen a este resultado y no es mi propósito aquí reconstruirlas. Tan sólo aludiré a 5.542, en donde Wittgenstein establece la complejidad de los estados mentales y de la pauta para la construcción del sujeto, el cual resulta de una agrupación coordinada de ellos. Wittgenstein infiere en 5.5421 que "el alma - el sujeto, etc. - tal como se le concibe en la actual sicología superficial, es un absurdo".

En verdad un alma compuesta ya no sería un alma". ${ }^{18}$ Pero una vez rechazada el alma, nos encontramos en la vía del rechazo definitivo de la significatividad - no se diga ya de la verdad-del discurso sobre la inmortalidad. De este modo, sobre la base del atomismo ontológico y de la Teoría Pictórica, Wittgenstein está en posición de comunicarnos que "Así, pues, con la muerte el mundo no se transforma, sino cesa". ${ }^{19}$ Esto, naturalmente, es así porque "La muerte no es un acontecimiento de la vida: no vivimos para experimentar

\footnotetext{
17 Ibid., 6.421 (c).

18 Ibid., 5.5421 .

19 Ibid., 6.431 .
} 
la muerte". ${ }^{20}$ Esto último, obviamente, no sería el caso si el alma fuera una entidad real, pero Wittgenstein ya ha desechado esa posibilidad. En verdad, las consideraciones sobre la muerte y sobre temas relacionados (e.g., el sentido de la vida, la existencia de Dios, la naturaleza de Lo Bueno, etc.) no son sino consecuencias lógicas de lo establecido por la teoría del lenguaje.

Son estos pensamientos los que llevan a Wittgenstein a una genial intuición, presente en los Notebooks pero curiosamente ausente en el Tractatus, que él expresa diciendo que "Sólo de la conciencia de la unicidad de mi vida surge la religión - la ciencia- y el arte". ${ }^{21}$ El esclarecimiento de este pasmoso pensamiento requiere, sin embargo, que lo liguemos con otros.

Hay por los menos dos pensamientos relevantes directamente conectados con el mencionado en el párrafo anterior. El primero, que es el más importante, es el bien conocido de que "La ética es trascendental". $22 \mathrm{El}$ "sentido" de este pronunciamiento resulta evidente una vez que se ha aprehendido el mensaje de la Teoría Pictórica. Recordemos que, de acuerdo con ésta, el discurso significativo, el lenguaje, sólo puede representar hechos. El pensamiento, por su parte, no es otra cosa que una figura lógica de un hecho. ${ }^{23}$ Los hechos son, naturalmente, contingentes, ya que las proposiciones, que son lo que los enuncia, se caracterizan por su bipolaridad. Es claro, sin embargo, que la ética trata de aquello que tiene un valor en sí mismo y no meramente gracias a algún feliz azar o por cumplir una función determinada, considerada útil o placentera. Una proposición ética tendría que ser un retrato o una figura de un hecho ético y, por lo tanto, tendría que ser informativa y necesaria, o sea, sintética a priori. Sin embargo, "No hay figuras que sean verdaderas a priori". ${ }^{24}$ No puede haber, por lo tanto, proposiciones éticas, lo cual no es más que otra manera de decir que la ética es inexpresable o trascendental.

Ahora bien, si la ética es trascendental, entonces, los esfuerzos por formularla conducen necesariamente a sinsentidos (no necesariamente a absurdos). Una tautología, por ejemplo, es un sinsentido, es decir, es una expresión que no apunta, a pesar de las apariencias, a ningún hecho en el espacio lógico. Si hubiera una genuina proposición ética, ésta debería no ser ni un sinsentido ni un absurdo. Para poner a prueba este resultado, examinemos lo que, siguiendo a Bouveresse, podríamos llamar el 'imperativo categórico supremo' de la ética de Wittgenstein: 'Se feliz'. ${ }^{25}$ Es relativamente claro que si comprendemos el significado de 'feliz', el mandato de que seamos felices resulta enteramente

20 Ibid., 6.4311.

21 Notcbooks, p. 79.

22 Tractatus, 6.421 (b).

23 Ibid, 3.

24 Ibid., 2.225.

25 J. Bouveresse, La Rime at la Raison, Les Editions de Minuit, París (1973), pp. 86-87 y passim. 
redundante. "Regreso una y otra vez a esto: la vida feliz es sencillamente buena, la infeliz mala. Y si ahora se me pregunta: pero ¿́por qué debo yo vivir felizmente?, esto en sí mismo me parece ser una pregunta tautológica". ${ }^{26}$ Los principios éticos son, en verdad, inexpresables.

No obstante, Wittgenstein de todos modos intenta establecer una conexión sintética entre los diversos resultados, aún a sabiendas de su ilegitimidad lógico-semántica. La conciencia de la unicidad de mi vida, es decir, de que mi vida tiene límites, me hace querer no sólo disfrutarla materialmente sino, también, ser feliz, en donde 'ser feliz' no significa nada relacionado con el placer mundano, con ninguna clase de consumismo, con la colección de satisfacciones prosaicas. La felicidad que procede de la conciencia de la unicidad de la vida es de carácter ético y, por ello, también es trascendental, esto es, inexpresable,

Pero podríamos decir: la vida feliz parece ser en algún sentido más armoniosa que la infeliz. Pero ¿en qué sentido?.

¿Cuál es la marca objetiva de la vida feliz, armoniosa? Aquí es claro una vez más que no puede haber una marca así que pueda describirse.

Esta marca no puede ser una marca física sino sólo una metafísica, una trascendental. ${ }^{27}$

De ahí que, al final de cuentas, lo único que pueda decirse sea, simplemente, que "El mundo del hombre feliz es diferente del mundo del hombre infeliz". ${ }^{88}$ Wittgenstein en un esfuerzo supremo por caracterizar de algún modo esta marca de la felicidad, recurre a la última forma de expresión por la que puede optar, i. e, la metáfora, y entonces nos dice que, dependiendo de nuestra bondad o maldad éticas, el mundo (es decir, el mundo de cada uno de nosostros, el mundo del sujeto ético) "se vuelve un mundo completamente diferente. Debe, por así decirlo, ensancharse o encogerse como un todo". ${ }^{29}$ Más no se puede decir, ni deberíamos intentarlo.

Si de la conciencia de la unicidad de nuestra existencia surge, como afirma Wittgenstein, la religión, no es menos cierto que en el núcleo de dicha intelección se encuentran motivos éticos. La religión se nos aparece entonces como una prolongación de la ética. El hombre que, consciente de su finitud, aspira a ser bueno, aspirará a ser eternamente bueno, a ser evaluado por un juez supremo, a tener alguna recompensa trascendental, etc. Es en la plasmación lingüística de estos anhelos y en las prácticas que dicho lenguaje fortifica y desarrolla que consiste la religión. Pero si lo que digo es cierto, ello tiene importantes consecuencias que es preciso hacer explícitas.

\footnotetext{
26 Notebooks, p. 78.

27 Ibid,p. 78.

28 Tractatus, 6.43 (c).

29 Ibid, 6.43 (b).
} 
Lo que ante todo hay que hacer es repetir y enfatizar que en la raíz de la conciencia religiosa se encuentra la conciencia ética. En la medida en que esta última emerge con la comprensión de la lógica del lenguaje y de sus límites, es la misma para todo usuario del lenguaje. Lo que de hecho son distintas (por sinnúmero de razones contingentes) son las religiones. Luego no puede hablarse de una conexión causal simple entre ética y religión y menos aún entre la ética y la interpretación usual de la religión. De ahí que sea lógicamente posible ser un sujeto ético, tener "experiencias" expresables en un lenguaje religioso y no estar comprometido con el teísmo tradicional, esto es, con la interpretación fácil y deformadora del lenguaje y las prácticas religiosas. $\mathrm{Pa}$ rece igualmente innegable que, por una multitud de factores, de hecho, sujetos éticos hay pocos (no es nada fácil comprender la lógica del lenguaje). Dada la importancia de la conciencia ética y de las experiencias religiosas (promovidas por el simbolismo mismo), lo que se ha hecho ha sido instituir ritos que, se ha pensado, le facilitan al usuario del lenguaje - o le acortan- el camino que conduce a la "experiencia" ética o el éxtasis religioso. Pero, dejando de lado el asunto de la calidad de la experiencia en cuestión, esto sólo parece ser posible sobre la base de una interpretación errada de la vida religiosa. No hay ni puede haber recetas para la auténtica experiencia mística: a ésta sólo se llega - si se llega - por la vía dolorosa de la comprensión. Pero, si lo que hasta aquí hemos dicho tiene visos de verdad, entonces queda claro que hay un modo de emplear los conceptos de fe, Dios y rezo que difiere del modo usual y que nos remite a lo que podríamos llamar 'genuina vida religiosa'. Y es ésta la que se nos aparece como el punto culminante en la secuencia de experiencias que llamamos 'vida'.

Intentemos presentar en forma sucinta lo que hemos estado haciendo. Uno de nuestros objetivos fue poner en claro diferencias gramaticales entre el lenguaje religioso y el laico. Vimos que hay ciertas exigencias lingüísticas y extralingüísticas que valen para el lenguaje de la fe laica y que no son idénticas a las que valen para el juego de lenguaje de la fe religiosa. Asimismo, vimos que "Dios" no es un concepto que pudiera pertenecer a la familia constituida por los conceptos de experiencia. Esto implica, entre otras cosas, que cuando se emplean expresiones como 'hablarle a Dios', el sentido de las expresiones en cuestión no puede ser tomado literalmente, como se hace cuando 'hablar' se aplica para dirigirse a, e.g., otra persona (directamente, por teléfono, etc.) Es mi opinión que asimilar el juego de lenguaje religioso al descriptivo es hacer de la religión superstición y de la vida religiosa una superchería. Estoy persuadido, asimismo, de que es esto algo que debe evitarse a toda costa.

La comprensión de la vida religiosa que podría generar la filosofía wittgensteiniana es aquella que emerge gracias a la elucidación gramatical. Esta última es el examen de los juegos de lenguaje y, por consiguiente, de las formas de vida. La comprensión deseada se logra cuando se llega a tener una 
visión perspicua del sistema de conexiones que rigen a las expresiones de un juego de lenguaje particular. Para ello, como ya sabemos, es preciso describir el uso de las expresiones en cuestión y ello no puede ser un ejercicio $a$ priori: se requiere la consideración de casos y situaciones concretas. A lo que mediante nuestro examen aspirábamos era, sencillamente, a poner de relieve peculiaridades del juego de lenguaje religioso y a enfatizar diferencias con juegos de lenguaje más usuales (e.g., el de la descripción del mundo). El lenguaje religioso es, claramente, sui generis. Su función, por lo tanto, tiene que ser otra que la de describir el mundo. Podemos tal vez presentar el resultado de este modo: si, siguiendo en esto al Tractatus, asociamos pensamientos genuinos con la enunciación de hechos del mundo (o de hechos en el espacio lógico), entonces, habrá que decir que el lenguaje religioso no sirve para expresar pensamientos. No se sigue, empero, que dicho lenguaje sea asignificativo o inútil. Nuestro problema era, entonces, determinar cuál podría ser su función. Fundándome en lo dicho a lo largo del trabajo, pienso que el lenguaje religioso abre las posibilidades tanto para la auto-representación como para la expresión de lo que podríamos llamar las 'experiencias supremas' o las más 'excelsas'. Es muy importante señalar que, si bien podemos permitirnos hablar de "experiencias religiosas" o, incluso, de "experiencias místicas", nuestro trabajo de investigación nos salva del compromiso con experiencias super-naturales y con entidades trascendentes. Las aclaraciones que aquí he ofrecido y la perspectiva general a la que conducen chocan frontalmente con eso que no es sino la interpretación usual de las vivencias religiosas.

Quisiera, para terminar, ofrecer mi conclusión como respuesta a la pregunta con la que se inició el trabajo. Me parece que el dictum de Spinoza es válido en este contexto. La comprensión de la vida religiosa, es decir, de la lógica del lenguaje religioso y de las prácticas religiosas, inevitablemente opera una transformación en el “creyente”. A éste la única opción que entonces le está vedada es la de la interpretación inculcada y asimilada a ciegas y que fluye por los canales de la acción pre-reflexiva y dogmática. 